Dialectologia 24 (2020), 221-251.

ISSN: 2013-2247

Received 17 December 2017.

Accepted 3 May 2018.

\title{
A LINGUISTIC STUDY OF MANIPULATIVE ADVERTISING STRATEGIES OF THE MOBILE NETWORK OPERATORS IN EGYPT AND THE UNITED STATES. COMPARATIVE APPROACH
}

\author{
Ahmad Abdel Tawwab Sharaf ElDIN \\ Menoufia University * \\ brave107@gmail.com
}

\begin{abstract}
Advertising nowadays penetrates all aspects of our daily life: on TV, the radio, in the newspapers, in the mailboxes, on the side of underground metro, etc. Whether advertising is annoying or amusing, useful or misleading, it is a form of communication whereby advertisers communicate the value of a product or service to customers. However, advertising is far from just being informative in an innocent and straightforward way. Advertising has an agenda. It is a skillfully constructed message, which manipulates the viewers' culturally created perceptions and aspirations, and which presents the advertised product as a way to satisfy the audience's desires. This happens by creating a specific image for the advertised stuff and building the viewers' perception of such ads.

Advertising is also about establishing a relationship between the advertiser and the viewer and it is important to look at this relationship as it helps to form the consumers' behavior towards the advertised product. Academic contributions on the linguistic features of advertising appeared few decades and developed into a rich interdisciplinary field of study. Advertising has attracted consistent and intense attention across academic disciplines including marketing, media studies, psychology, sociology, and linguistics.

From a linguistic dimension, advertising research focused heavily on the description of specific textual devices or the relations between text and image, and certain pragmatic features, which view

\footnotetext{
* Menoufia University, Faculty of Arts, Department of English Language \& Linguistics, Shibeen II Koum City, Menoufia Governorate, Egypt (7001).
} 
advertising as a special concept of discourse. In this sense some important questions remain unapproached, like, how are the addressees motivated to tackle and process linguistic notions in advertising and what are the strategies to manipulate their mental concepts.

\section{Keywords}

language, manipulation, advertising, discourse, generalization, vagueness

\section{ESTUDIO LINGÜÍSTICO DE LAS ESTRATEGIAS DE PUBLICIDAD MANIPULATIVA DE LOS OPERADORES DE RED MÓVIL EN EGIPTO Y EL ENFOQUE COMPARATIVO DE LOS ESTADOS UNIDOS}

\section{Resumen}

Hoy en día la publicidad penetra en todos los aspectos de nuestra vida cotidiana: en la televisión, la radio, en los periódicos, en los buzones, en el metro, etc. Tanto si la publicidad es molesta o divertida, útil o engañosa, es una forma de comunicación mediante la cual los anunciantes comunican el valor de un producto o servicio a los clientes. Sin embargo, la publicidad está lejos de ser simplemente informativa de una manera inocente y directa. La publicidad tiene una agenda. Es un mensaje hábilmente construido, que manipula las percepciones y aspiraciones culturales de los espectadores, y que presenta el producto anunciado como una forma de satisfacer los deseos de la audiencia. Esto sucede creando una imagen específica para el material publicitado y construyendo la percepción de los espectadores sobre dichos anuncios.

La publicidad también trata de establecer una relación entre el anunciante y el espectador y es importante tener en cuenta esta relación, ya que ayuda a formar el comportamiento de los consumidores hacia el producto anunciado. Las contribuciones académicas sobre las características lingüísticas de la publicidad aparecieron hace pocas décadas y se convirtieron en un rico campo de estudio interdisciplinario. La publicidad ha atraído una atención constante e intensa en todas las disciplinas académicas, incluyendo marketing, estudios de medios de comunicación, psicología, sociología y lingüística.

Desde una dimensión lingüística, la investigación publicitaria se centró en gran medida en la descripción de dispositivos textuales específicos o en las relaciones entre texto e imagen, y ciertas características pragmáticas, que ven la publicidad como un concepto especial del discurso. En este sentido, algunas preguntas importantes siguen sin abordarse, como, por ejemplo, ¿cómo están motivados los destinatarios para abordar y procesar las nociones lingüísticas en la publicidad y cuáles son las estrategias para manipular sus conceptos mentales?

\section{Palabras clave}

lengua, manipulación, publicidad, discurso, generalización, vaguedad 


\section{Introduction}

Language and advertising are important notions in our society. There are many forms of advertising, and there are tens of papers written in favor of or against advertising as Motes et al. (1992), Fatihi (1992) and others. Thus, advertising is a subject by whom many people have an opinion, and it can be evaluated from different points of view. In this study, it will be evaluated-from-a-linguistic-point-of-view.

The goal of advertising is to motivate behavior, to sell a product, a service, or an idea (Goddard 1998, Abd Alhamid 2007). Therefore, to accomplish these goals, there should be an understanding of the relationship between the linguistic theory of text analysis and advertising so that consumers can decide between the various alternatives in the marketplace. When this happens and the consumer reacts to the advertisement, one can say that this advertisement achieves its goals. Obviously, these goals depend on the use of language and how the language of advertising can convey a certain message.

In this regard, it is worth mentioning that advertising is a form of discourse which makes a powerful contribution to how we construct out identities, and how the language of advertisements affects us and means something to us. Since it is assumed that a conversation adheres to Grice's maxims (Brown \& Yule 1983; Crystal 1997) and these maxims apply to behavior in general, then it must also be assumed that these maxims also apply to advertising discourses, especially in the manner maxim. Therefore, the focus of this study is to provide a comparative study of the linguistic manipulation in Egypt and the US as this is used in different contexts of advertising discourse.

Discursively, advertising is a pragmatic type of discourse, which functions in accordance with its main goal - to turn linguistic and visual message into an act of purchasing and in this regard directly depends on who the discourse participants are and the relationship between them. There is no question that language is a major component of most advertising. Words, phrases, and sentences are used in advertising to convey information, to influence attitudes and to affect behavior. Selecting appropriate terminology and the creative use is something essential, therefore advertisers use a 
variety of tools in their creative marketing campaigns in order to make viewers yield to their messages

Among all the components of ads (music, moving pictures, spoken and sung language, and writing on the screen) that contribute to their overall meaning, the linguistic component is central. Despite a preponderance of research on advertising language relatively scant, attention has been devoted to the fact that "ads represent a variety of discourse scenarios involving a variety of discourse participants" (Chapman 2001: 22).

It is important to mention that advertiser employs words and meanings in order to achieve specific marketing goals with a particular target audience. In determining the language to be used, decisions are often made to break the commonly accepted rules of the language used. Vodafone advertising, as a sample, which states that the power is in the hands of its customers is an example. The advertiser apparently used for employing few utterances as opposed to using correct grammar for a reason, as will be shown in the following pages. Presumably this is done to communicate more effectively. Rules of grammar also may be broken as a device to attract attention.

\section{Purpose of the Study}

This study attempts to conduct a linguistic analysis of randomly selected samples of advertisements in Egypt and the US. This study will deal with different features of lexical features in the selected samples. That will also include the manipulative strategies, invented by Van Dijk (2006) on the three levels, cognitive, social, and discursive. These lexical features will be related to appeals, the style of meaning it conveys, the kind of the semantic means, the sort of claim that is used in it, collocation of word, spelling abbreviations, and manipulative strategies in the selected samples.

The goal of this study is twofold: to investigate the underlying mechanisms of advertising responsible for changes in consumer behavior and to contribute to an understanding of the process of linguistic manipulation, particularly as it occurs in the contexts of advertising. Moreover, it investigates various kinds of mechanisms that 
advertisers employ to gain the audience's interest through the verbal and non-verbal information and communicative procedures intended to make them act on it.

\section{Research Questions}

In order to achieve the above research objective, it is necessary to formulate the following research questions. Basically, this study focuses on the linguistic and cognitive features in the mechanism of advertising in Egypt and the United States. Therefore, it attempts to shed lights on the followings; what are the manipulative strategies/ways employed in the advertising to form the mental models of the audience? And how linguistic aspects are deeply correlated with such cognitive model in the manipulation? And what are the specific rhetorical devices that could be used effectively to influence the audience?

\section{Problem Statement / Hypothesis}

It is noticed that advertising is related to many aspects of the human life such as the economic, the social, the educational and the cultural aspects. In other words, advertising does not exist and work independently or alone. Bearing this fact in mind, in addition to its costly expenditure, advertising has become worthy to be studied. Thus, there have been many studies that investigated some important aspects of advertising such as its effects on sales and the consumer's experience with the product in addition to its cognitive effects

The language of advertising, on the other hand, only recently has gained the interest of linguists. As a result, many studies have been conducted concerning advertising: truth, deception of consumers, difficulty, syntax and style. This research attempts to examine advertising's relation to such issues as manipulation, persuasion, the 
internal structure of an advertising's discourse and how to expose manipulative strategies in advertising.

A large body of this linguistic research has concentrated on mobile phones commercials in mass media. This emphasis may be justifiable because of the overwhelming interest in television, in general, which provides the public with different kinds of information using both of text and picture. The language of print advertising, in general, has gained less attention. This is perhaps because some people think that the printed ads alone consisting of only one or two sentences cannot provide a complete and useful meaning.

Some people, on the other hand, may think that a headline has to rely on the rest of the advertisement in order to provide consumers with a significant meaning. Nevertheless, print material which is conveyed to people using specifically newspapers and magazines is still of great value and importance in communicating information. Otherwise we will not find that huge number of newspapers around the world and that vast number of advertisements if we go over one issue of any newspaper.

\section{Data and Methodology}

The small-size corpus of analysis consists of eight samples of randomly selected advertisings that are employed in the US and Egypt. Such advertisings represent the most famous mobile phones companies both in the US and Egypt. From the US, the mobile phones companies are AT\&T, Verizon, and T Mobile. From the Egyptian side, advertisings represent three companies; Vodafone, Orange, and Etisalat.

The analyzed samples of advertisings are randomly selected during the period from 2016 to 2017; they represent many of similar topics which convey more or less various messages. In this research, few strategies will be examined under the coverage of linguistic manipulation of whether it is a positive of a negative linguistic way of manipulating the audience. 


\section{Language Manipulation}

Language manipulation is shown in the vagueness employed in advertisements. Few scholars including El-Hinnawi (1992: 33) believe that it is quite crucial for the readers of advertising to have a careful understanding of the ambiguities in any material they read so they can protect themselves against the deliberate ambiguities which are used by advertisers The advertisers usually do not give full details about the product. According to El-Hinnawi (1992: 33), such language manipulation could be reflected on three dimensions:

1- To what extent such advertisements are highly readable and written by professional writers who try to convince their audience.

2- Such advertisements focus on specific idea or a topic with much redundancy.

3- Cultural information is highly used in advertising.

Shabbir \& Thwaites (2007) explain that the identification of types of manipulation strategies in the ads could be seen to occur through three mechanisms:

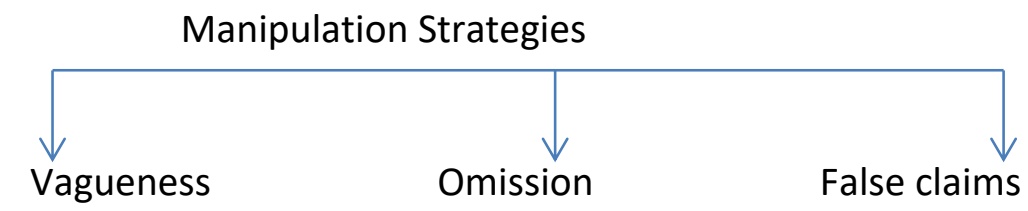

a) Vague/ambiguous: The claim is overly vague or ambiguous; it contains a phrase or statement that is too broad to have a clear meaning. Example: Ad for a building society-have a future that never ends by becoming a customer, or a mobile network company gives its slogan الحياة بتتغير مع أورنج "Life changes with Orange” (too vague to have a specific meaning).

b) Omission: The claim omits important information necessary to evaluate its truthfulness or reasonableness. Example: Ad for an insurance company which promises to 
give an "attractive quote" (but does not state that giving the quote is conditional on meeting certain requirements that would disqualify some potential customers).

c) False/outright lie: The claim is inaccurate or a fabrication. Example: Ad for Vodafone القوة بين إيديك (Power in your hands) that viewers can get anything they want. This suggests that users can get anything they want in life by using this hair spray. This very broad generalization makes the ad to be false.

\section{Significance of Advertising}

The importance of advertising has been growing in the modern society of many countries nowadays. This importance is evident in these societies in many aspects of their economic, social, educational and cultural systems. The United States of America is one example of these countries in which the importance of advertising can be noticed. In the economic system, this importance is evident in the statistical reports which show that billions of dollars are spent on advertising each year.

In the social system, advertising provides consumers with the information they need so that they can decide what specific product to buy. Here, advertising makes something well-known and familiar to people. Treasure (1974: 2) continues that advertising fulfills its social role in society by implementing the process of familiarization. The social value here, the author proceeds, is making people secure and comfortable. Advertising plays its educational role when it fulfills its most important and basic function which is communicating information including both facts and impressions.

\section{Functions of Advertising}

According to Shavitt et al. (1992), advertising has five main functions; they are societal, economical, entertaining, informative and hold certain degree of credibility. When ad advertising has a social or informative function, it certainly adds to the credibility of the advertising. This is because the societal function of the advertising helps 
in serving the benefit of the society and the welfare of consumers, which could increase the credibility of the commercial companies and its product.

There is no question that the informativeness in the ad affects the consumer's awareness of specific products. That could influence the consumer's reaction towards certain products and how they understand the ads based on the information they receive and whether it is helpful for them, or not.

The other function "entertainment" is the clearest sign of the attitude of the consumers toward the advertising. Since advertising is broadcasted on a daily basis, so the more entertaining, the more effective. The credibility point is based upon the factful elements in the advertising. Such credibility could be completed from the attitude of the consumer and cumulative experience with a particular ad. This depends on the past experience of watching or listening to advertising. The degree of confidence is what make consumers depend on and trust any ad with certainty.

\section{Characteristics of Advertising}

The texts of any printing advertising are considered as the shortest structures of sentences where each word in each advertisement does hold a meaning towards the shaping of the intended meaning. For this reason, the text type of advertising should be characterized by a set of lexical, syntactic, and stylistic features and the totality of which should give such a text its identity and make its social function.

Some of the main characteristics of advertising are mentioned in Motes et al. (1992) characteristics of advertising. These characteristics include the use of personal reference, interrogative and imperative sentence structures. Other comprehensive characteristics include verbless, subjectiveless, and syntactless words, in addition to appropriate contextual (e.g. the location of such a text) and intra- textual elements (e.g. lexical, semantic, and syntactic). Other features will include the following; simple sentences or phrases, eye-catching title or headline, more emotion with less information, preference for photograph, words or phrases in English or other languages, metaphors and 
colloquialisms or spoken language, brand names: trademark or trade name. On the lexical level, there are certain strategies:

1- Ellipsis: The omission of part of a structure. The advertiser can use ellipsis to create a casual and informal relation with the recipient

2- Reference words: symbols or names which are used to identify or explain the meaning of certain lexical items

3- Certain kinds of words: the use of certain expressions related to subject of the message interrogative and imperative sentence structures

\section{Manipulation in Advertising}

Manipulation is one of the issues that are often raised by scholars of communication. However, every researcher that approaches this issue, no matter what field they work in (political science, psychology, linguistics or marketing), is aware of the vagueness and the absence of clear-cut definitions for this term. Defining manipulation in terms of human behavior or linguistic and communicative behavior is especially challenging.

For Geis (1982) judging an advertisement's deceptiveness involves not only evaluating truth assumptions of the explicit claim it makes, but also determining how viewers get a given claim in context. Geis notes that advertisers can deceive the audience in a number of ways: by asserting or implying a false belief, by allowing someone to acquire false belief and by presenting lengthy disclaimers that are impossible to read in the time allowed. He further argues that definitions of manipulation and persuasion are particularly satisfactory. "The term manipulation is pejorative, and the term persuasion focuses too much on the ratiocinative, as opposed to affective, side of persuasion" (Geis 1982: 20).

Geis makes use of McGuire's (1969) information processing model which views persuasion as a process in which "a source presents a message to a receiver via some communication channel in an attempt to effect either of two behavioral changes: for the receiver to believe that the message is true, or for the receiver to act upon this message" 
(Geis 1982: 20). According to Geis, manipulation differs from persuasion in that in manipulation "there is no conscious evaluation by the receiver of the merits of the source's message" (Geis 1982: 21).

Medvedeva (2003) assigns mass advertisement to manipulative discourse, which is characterized by its main goal - to cause a desire in recipients by appealing to the rational, the emotional and the subconscious. She compares manipulation to propaganda claiming that the difference between the two is only in their names, since they serve one purpose - to brainwash - and thus, are essentially the same (Medvedeva 2003: 102). She exemplifies some of the manipulative techniques, such as imposition of one's opinion, use of rich linguistic imagery, imposition of presupposition, and the use of pseudoscientific terms. She does not provide a clear definition of manipulation, nor does she show the mechanisms that underlie such manipulation. She claims that manipulation differs from persuasion in that the recipient is deliberately deprived of the opportunity to objectively evaluate the content of the message. However, she does not specify how exactly this happens.

Manipulation, according to Wrong (1995: 28), is the concept of power holder concealing his intention to influence his listeners to follow his wishes. Such an exercise of power is unlikely to evoke resistance of power as a person is unaware of the effort to influence him. Yet, such apparently positive uses of manipulation have not escaped the suspicion that cling to this form of power, a suspicion aroused by the person's ignorance as to whether he has been manipulated and the manipulator's concealed purpose.

Manipulation may also occur where there is no social relation between the advertiser and the audience and the latter may not even be aware of the advertiser influence. This can take the form that advertisers may exercise concealed control over the subject through symbolic communications designed to make veiled suggestions, to limit or determine selectivity of the advertised subject. However, manipulation has a more negative reputation than perhaps any other form of power, suggesting cunning and malign purpose on the part of the manipulator. It is a form of power that cannot be openly resisted by the audience, since he/she is unaware of the advertiser's real intent. 
Chilton (2005: 16) defines manipulation in terms of an addresser's "intention to deceive, lure or inspire, or in terms of an addressee being unconsciously thoughtcontrolled". According to Chilton, manipulation is a "forceful spreading of ideas which depends largely on the ability of the propagator to control or dominate an intended receiver's mind by controlling the channel of communication or depriving the receiver of the potential to verify" (Chilton 2005: 17). He notes however, that the effect of manipulation is very unpredictable, since it is the 'cognitive ingredients' in readers' heads put together guided by the linguistic input that play principal role in manipulation.

Chapman (2001) uses Yokoyama's definition of manipulation and applies it to her discourse model. According to Chapman, it is the manipulative nature of advertising that creates a psychological link between the fictional and real-world components of an ad. This link functions "as the source of the two knowledge items that the advertiser intends to convey to the recipient" (Chapman 2001: 60).

Manipulation, according to Van Dijk (2006), is a social phenomenon especially because it involves interaction and power abuse between groups and social actors - a cognitive phenomenon because manipulation always implies the manipulation of the minds of participants, and a discursive-semiotic phenomenon, because manipulation is being exercised through text, talk and visual messages. All three elements (social, cognitive, and discursive), are needed in an integrated theory that also establishes explicit links between the different dimensions of manipulation.

Van Dijk's Classification of Manipulation

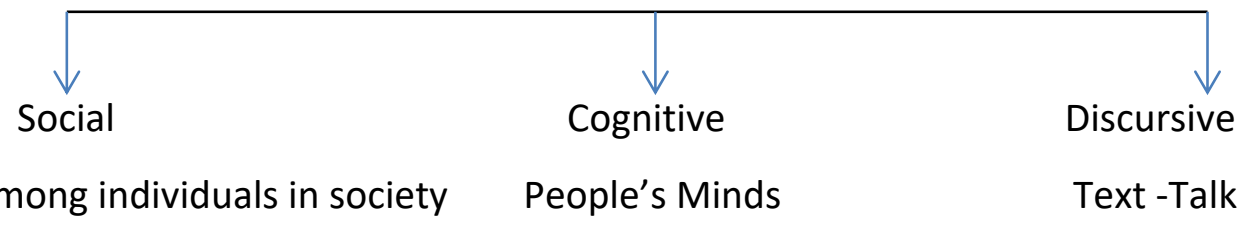

Van Dijk proposes that manipulative communicators intentionally not to provide recipients with complete accurate picture of their beliefs, or more actively, they provide them with relatively inaccurate picture. He attempts to distinguish between, say, 
deception and persuasion, two forms of manipulation that refer to two realities - the world of truth and facts and the world of value, or cultural evaluations.

Van Dijk (2006) explains that manipulation not only involves power, but specifically abuse of power, that is, domination. That is, manipulation implies the exercise of a form of illegitimate influence by means of discourse: manipulators make others believe or do things that are in the interest of the manipulator, and against the best interests of the manipulated

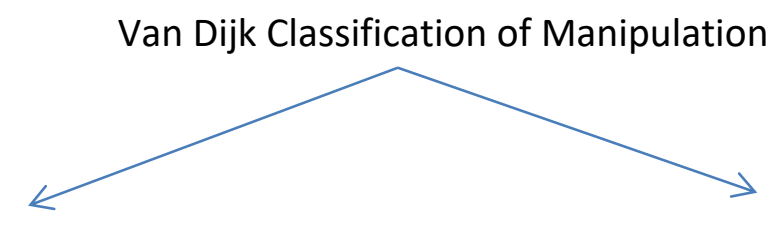

Positive Association

Legitimate persuasion

Free to choose or to believe
Negative Association

unable to understand the real intentions of the manipulator lack the specific knowledge to resist manipulation

Without the negative associations, manipulation could be a form of (legitimate) persuasion. The crucial difference in this case is that in persuasion the interlocutors are free to believe or act as they please, depending on whether or not they accept the arguments of the persuader. Obviously, the boundary between (illegitimate) manipulation and (legitimate) persuasion is fuzzy, and context dependent: some recipients may be manipulated by a message that is unable to manipulate others.

Nettel \& Roque (2011) are clear in make a distinction between persuasion and manipulation. Persuasion is the action undertaken by people looking to change the opinion of others. It is usually done with a good intent and by having the interest of the others in mind. Persuasion implies making someone change their opinion. Transparency is key and essential when it comes to persuasion. People understand why others may feel the need to convince them of something. In her evaluation for the main distinction between both concepts, Medvedeva (2003) claims that manipulation differs from persuasion in that the recipient is deliberately deprived of the opportunity to objectively evaluate the content of the message. Chilton (2005: 16) lays out the notion of 
manipulation. He mentions that it is a "forceful spreading of ideas which depends largely on the ability of the propagator to control or dominate the receiver's mind by controlling the channel of communication or depriving the receiver of the potential to verify."

Manipulation, according to Nettel \& Roque (2011: 56), has specific features. They explain that one of the main features of manipulation is that it is eminently intentional: there is no manipulation without the intention to manipulate. Additionally, this criterion is fundamental: the intention to manipulate must remain hidden. Manipulators appeal to emotion and withhold vital information in an attempt to sway a person to a certain way of thinking. Manipulation implies concealed motives; therefore, the manipulator is subtly seeking to get someone to do things that are in his interests without revealing his true intention. If there is any sense of pushing someone to do something or to get something by using force or threats, in this way, it reflects the concept of coercion.

\subsection{Manipulation Techniques}

Manipulation strategies can be used in advertising no matter what the product is including the following categories:

1- Vague or ambiguous claims.

2- Claims that omit important information necessary to evaluate their truthfulness or reasonableness.

3- Claims that are false or outright lies, and various combinations of the previous categories.

\subsection{Institutional Power and Mobile Phones Companies}

In order to be able to exercise such social control of others, however, social actors need to satisfy personal and social criteria that enable them to influence others in the first place. Social conditions of manipulative control hence need to be formulated - at least at the macro level of analysis - in terms of group membership, institutional position, profession, material or symbolic resources and other factors that define the power of groups and their members. 
Van Dijk (2006) asserts the fact that manipulation is one of the discursive social practices of dominant groups geared towards the reproduction of their power. Such dominant groups may do so in many (other) ways as well, e.g. through persuasion, providing information, education, instruction and other social practices that are aimed at influencing the knowledge, beliefs and (indirectly) the actions of the recipients. Based on Van Dijk's perspective, manipulation generally focuses on social cognition, and hence on groups of people, rather than on individuals and their unique personal models. It is also in this sense that manipulation is a discursive practice that involves both cognitive and social dimensions and has certain strategies.

One of these strategies is generalization in which case a concrete specific example that has made an impact on people's mental models is generalized to more general knowledge or attitudes, or even fundamental ideologies. The most striking recent example Van Dijk (2006) tackles some cognitive mechanisms of manipulation. Thus, first of all a very emotional factor with a strong impact on people's mental models is being used in order to influence these mental models as desired - for instance in terms of a strong polarization between Us (good, innocent) and Them (evil, guilty).

Secondly, through repeated messages and the exploitation of related events (e.g. other terrorist attacks). Such a preferred model may be generalized to a more complex and stable social representation about terrorist attacks, or even an anti-terrorist ideology. Thus, one crucial cognitive condition of manipulation is that the targets (persons, groups, etc.) of manipulation are made to believe that some actions or policies are in their own interests, whereas in fact they are in the interests of the manipulators and their associates.

However, according to Van Dijk, he explains that manipulation could be detected and resisted. Indeed, one of the best ways to detect and resist manipulation attempts is specific knowledge (e.g. about the current interests of the manipulators) as well as general knowledge (e.g. about the strategies of maintaining the military budget at a high level). It will thus be in the best interests of dominant companies (Mobile phone network operator companies for example) to make sure that relevant and potentially critical 
general knowledge is not acquired, or that only partial or misguided knowledge is allowed distribution.

That being said, few linguists including Galasiński (2000: 21) consider manipulation as part of persuasion. There is an argument that persuasion is only a subset of manipulative strategies, at the same level as deception. Although a persuader sets out to induce a belief or attitude or, indeed, action on the part the addressee, and does it also without the addressee's realizing it, this is done by setting up a system of values to which persuadees are intended to subscribe. Targets of persuasion are made to believe that something is good or bad, rather than true or false. Rather than positioning deception and persuasion as a category within each other, they both can be seen as strategies that language users employ in laying out, or imposing, a preferred version of reality. At the highest level, both persuasion and manipulation are attempts at discursive representation.

\section{The Manipulative Advertising Techniques}

\subsection{Manipulation and Ellipsis}

The vast majority of researchers working in the field of advertising discourse consider ellipsis as "a trick intended to arouse the reader's curiosity" by which advertisers make their ads more memorable (Garnham \& Oakhill 1992, McQuarrie \& Mick 1996). Geis (1982), drawing attention to elliptical comparatives (e.g. "our oranges are sweeter"), calls them vague and states that advertisers use ellipsis in order not to make claims they cannot defend. Cook (2001) considers ellipsis to be a cohesive device, which has two major goals: to save space and omit some features that are not of interest to the advertiser and that may distract the audience's attention.

In addition, he suggests that through ellipsis advertisers try to avoid direct appeal in the age of the 'soft sell' (not-imposing like "you ought to use/buy", "we recommend", etc.). 
Ellipsis might indeed be used to attract attention and awaken the recipient's curiosity, particularly in printed ads when the lexical content is stripped to a bare minimum. However, in TV commercials, where the wealth of information is conveyed not only linguistically, but also visually, attracting viewers' attention is only one of the possibilities offered by this linguistic device, and the reasons for its frequent use in television advertising remain largely unexplained.

\subsection{Manipulation and Exaggeration}

An exaggeration can also be a form of puffery. Puffery is the term used to denote the exaggerations reasonably to be expected of a seller as to the degree of quality of his product, the truth or falsity of which cannot be precisely determined. Meanwhile, as quoted by Dandiu (2014), puffery is advertising claims that ordinary consumers do not take seriously. Claims such as "best deals, best network" for cellphones or "More control, more megabytes" are examples of puffery in the manipulation by advertising. The puffery seems to influence the people who are not major consumers of the product but turns away the consumers who are experts or have relatively high knowledge.
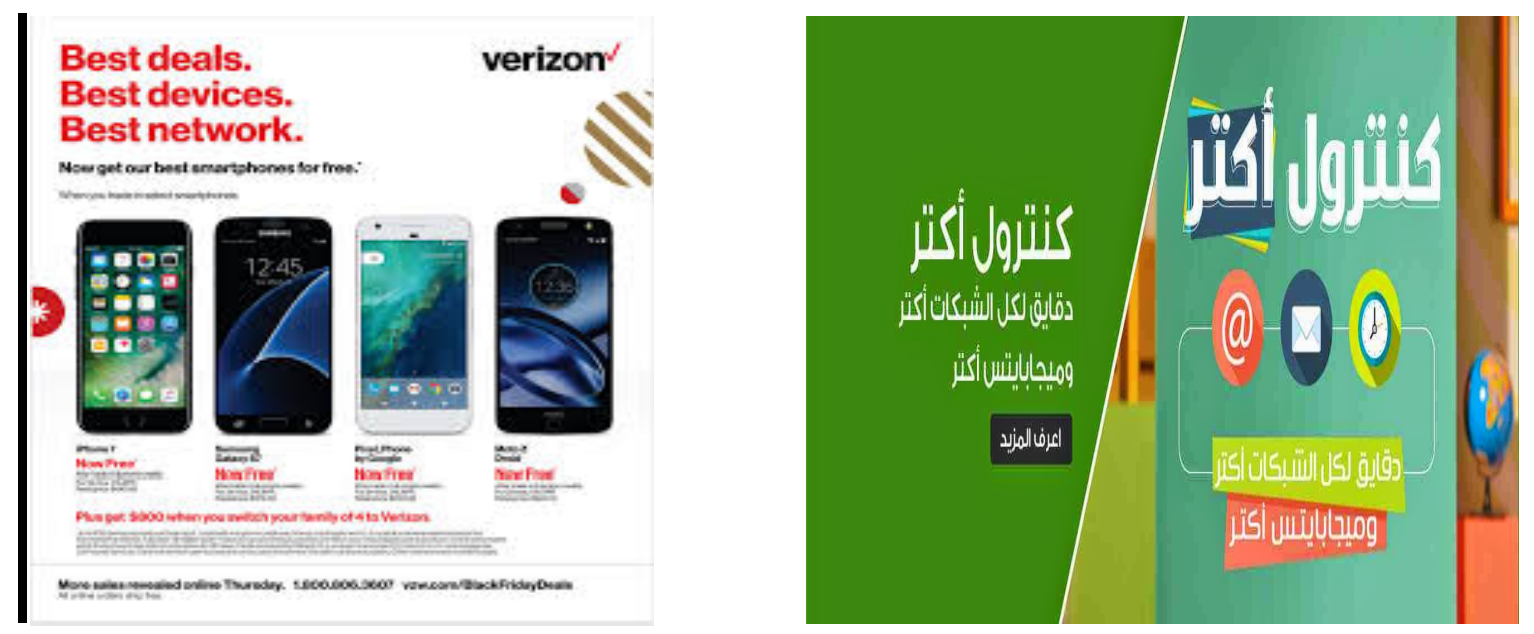

Figure 1. American advertising (Verizon Company). Figure 2. Egyptian advertising (Etisalat Company). 

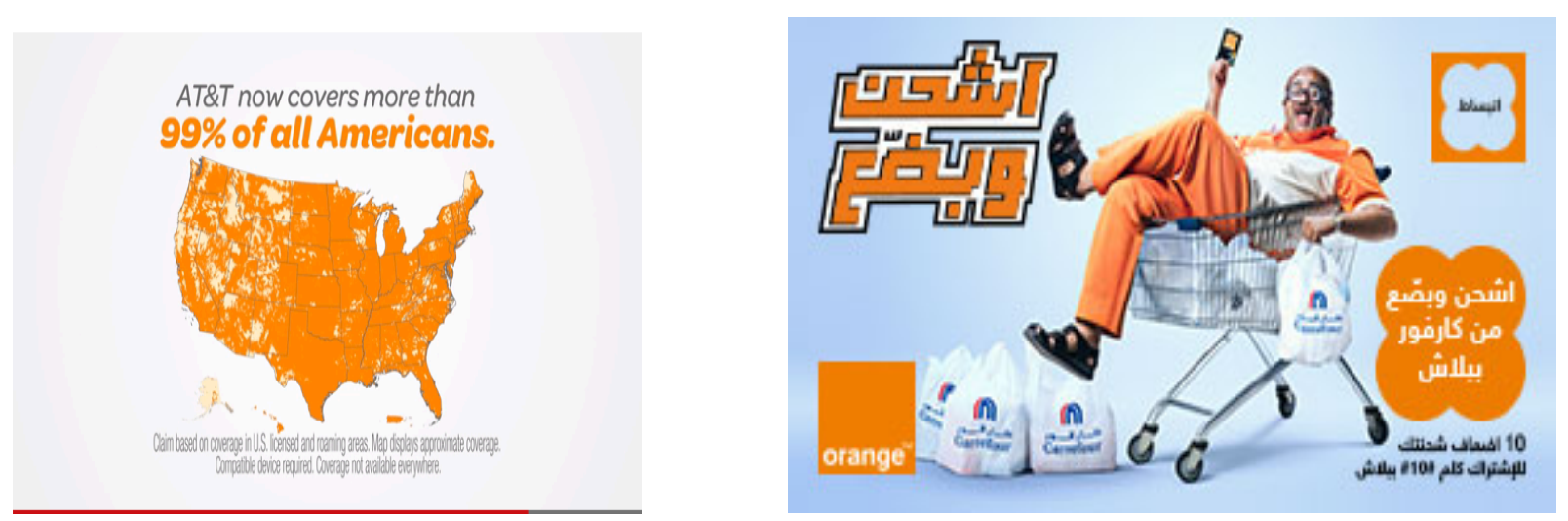

Figure 3. American advertising (Verizon Company). Figure 4. Egyptian advertising (Etisalat Company).

The above-mentioned example is a clear indication of such technique is advertising. Obviously, both Egyptian and the American advertising employed such technique. Therefore, it could be considered that exaggerations are not very useful for achieving the goals of advertising campaigns. The puffery could attract some new consumers but it could lose many consumers which are loyal to the product.

\subsection{Manipulation and Emotional Appeal}

Emotional appeals are the claims playing with consumers emotions both at conscious and unconscious level. In the advertisements can be included appeals to the need to achieve, dominate, feel safe, nurture, satisfy curiosity, the need of affiliation, guidance, prominence, attention, autonomy, physiological needs such as food, drink, sleep and so on.

\section{AT\&T}

Switch and save today. Join the AT\&T family. http://bit.ly/KyAiXM

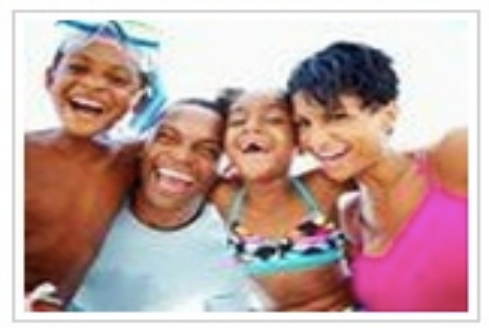

Like This Page

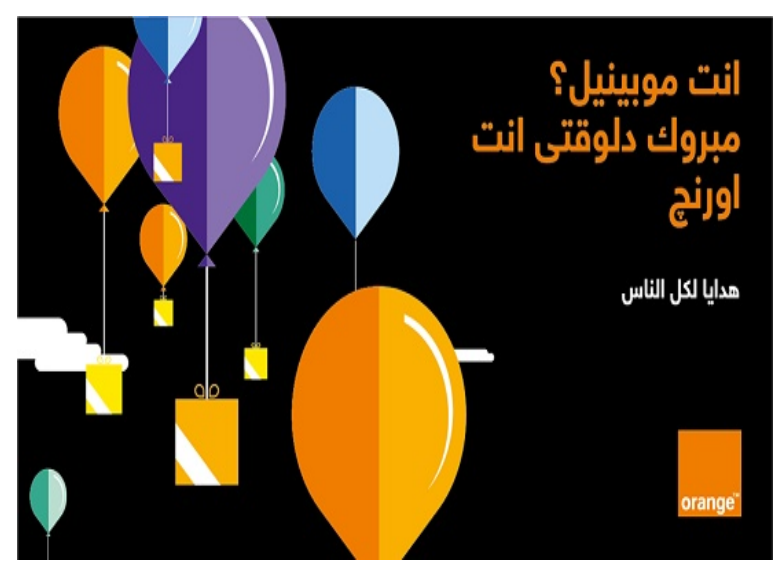

Figure 5. American advertising

Figure 6. Egyptian advertising 
In the above-mentioned ad, it looks like that both ads employed the emotions to grab the attention of their audience. In the American ad, it encourages the users to switch and save more money, Then it moves to the emotional side by mentioning the phrase "AT\&T family", which gives the impression like it is a big family and any new user should join such family to become a member and enjoy the benefits of such family. On the other hand, there is a similar technique activated here in the phrase (هدايا لكل الناس) translated in English as "presents for all people", which is another technique of manipulating the audience to become a member in this company.

\subsection{Manipulation and Rhetorical Devices in Advertising}

\subsubsection{Parallelism}

Parallelism is one of the forms of schematic pattering. It is defined by Leech (1972: 186) as "repetition of formal patterns". Schematic pattering occurs in all levels of language. Anaphora, epiphora, alliteration, assonance and antithesis also belong to techniques of schematic pattering (Wikipedia 2014: online). Parallelism means the parallel presentation of two or more than two structures.

\subsubsection{Anaphora}

Parallelism is often accompanied by anaphora "the deliberate repetition of the first part of the sentence in order to achieve an artistic effect".

- My life is my purpose. My life is my goal. My life is my inspiration. 


\subsubsection{Epiphora}

According to Wikipedia (2014: online), epiphora, on the other hand, is "the repetition of the same word or words at the end of successive phrases, clauses or sentences", as in:

- See new. Hear new. Feel new.

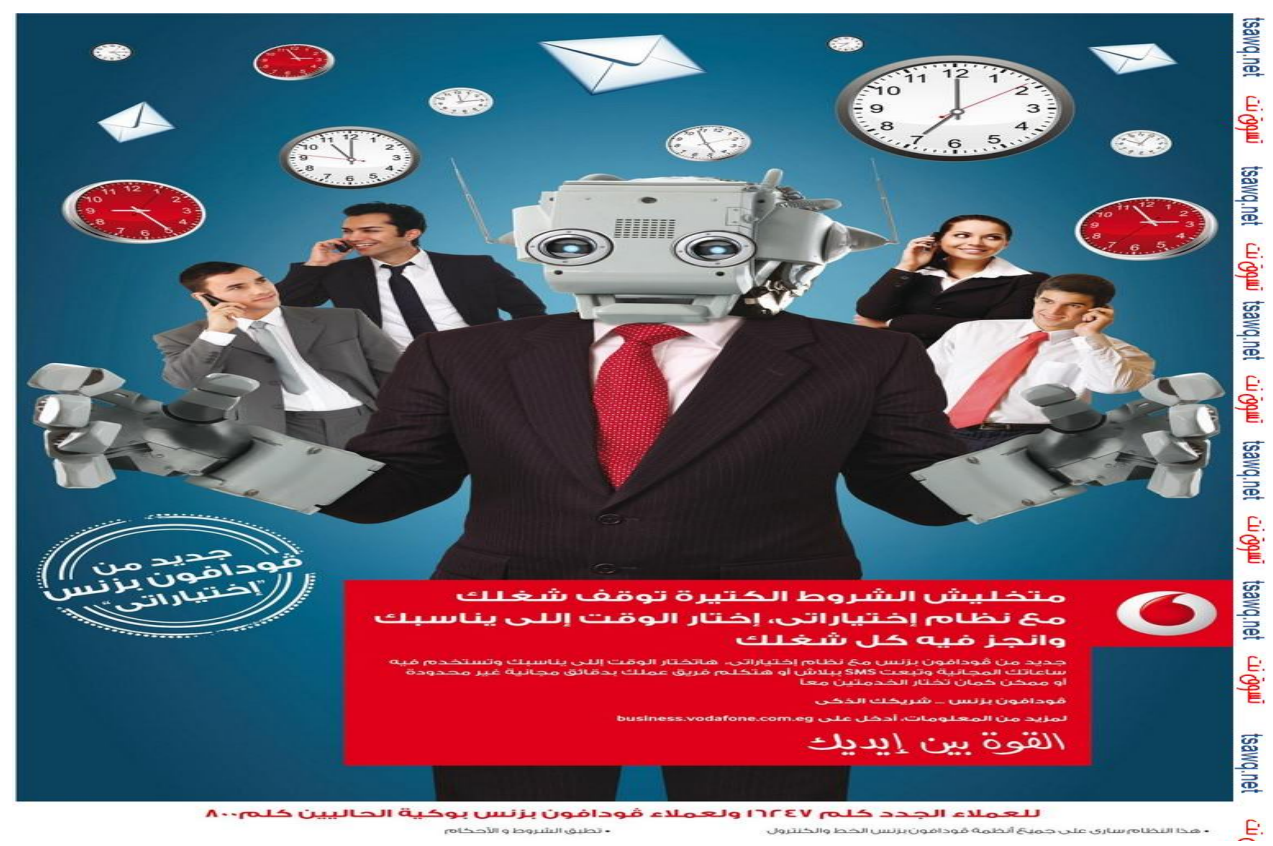

Figure 7. Egyptian advertising (Vodafone Company).

Here we have an epiphora example for the structure (توقف شغلك-كل شغلك) "all your work-stop your work".

\subsubsection{Antithesis}

Antithesis is a figure of speech, which uses the same or similar structure to express two opposite ideas so as to achieve the effects of emphasizing the meaning of contrast. The figure has the characteristics of harmonious combination of sound and rhyme, balanced syllables, sharp rhythm. The combination of pleasant senses of vision and 
Dialectologia 24 (2020), 221-251.

ISSN: 2013-2247

hearing often stimulates the good feelings of readers and arouses consumers' buying desire.

Antithesis is "fundamentally, contrasting ideas sharpened by the use of opposite or noticeably different meanings" (Cuddon 1999: 46). Antithesis relates to words, clauses or sentences. It is based on antonyms (words of opposite meaning or opposite ideas): for example, "Small seeds generate big ideas" (CNN).

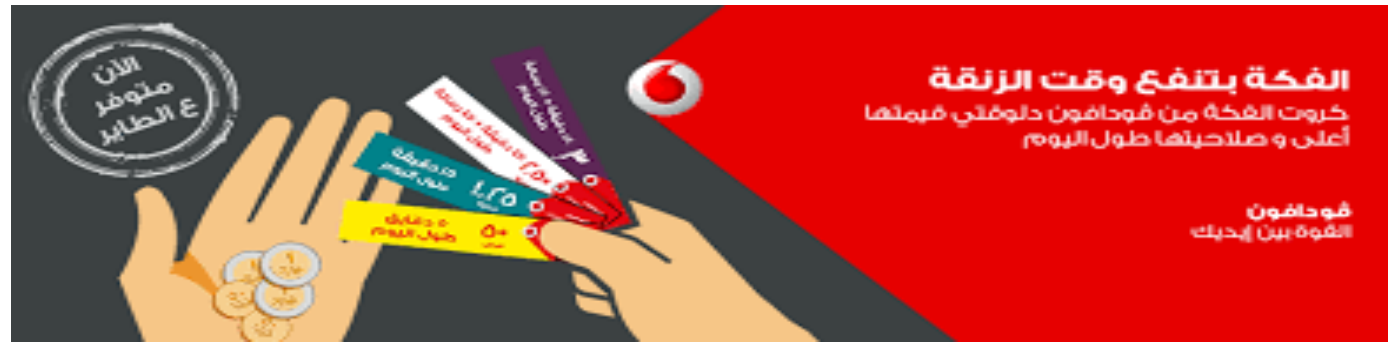

Figure 8. The Egyptian ad (antithesis of using the Arabic words; الفكة الزنقة Change money VS unchanging money.

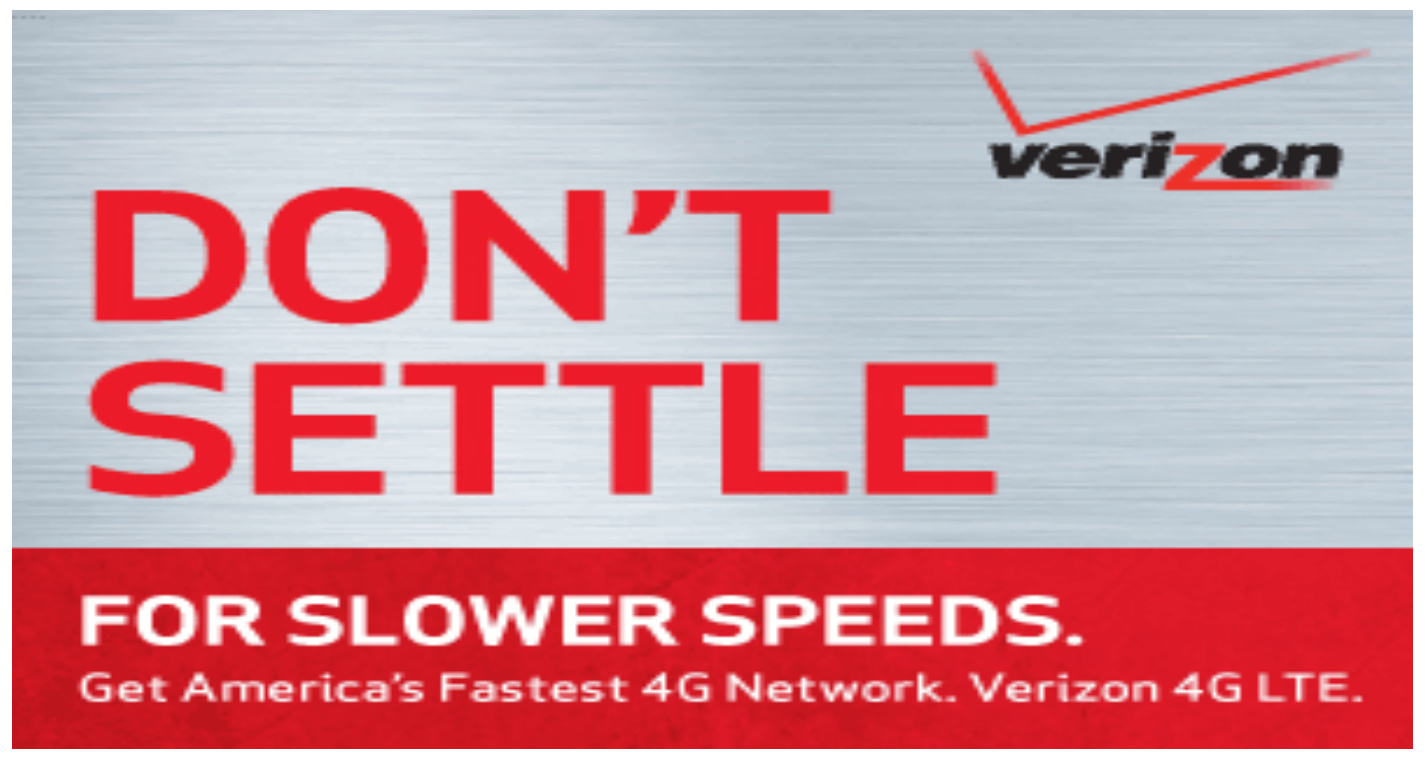

Figure 9. The American ad (slower VS Fastest).

One of the common characteristics of advertising is employing the following features: a) Simple sentences of phrases. b) Eye catching title or headline. c) More emotional with less information. c) Preference for photograph. 


\subsection{Synonymy}

It is important to shed lights on the uses this type of synonymy to write an effective and attractive advertisement with different forms, but, of course, with the same meaning and purpose. Therefore, the strategic function for using synonyms in advertising where they try to convince the reader or recipient to establish certain images about the truth of their proposition. They give the recipient examples to convince him of their interest, ability, and real hope.

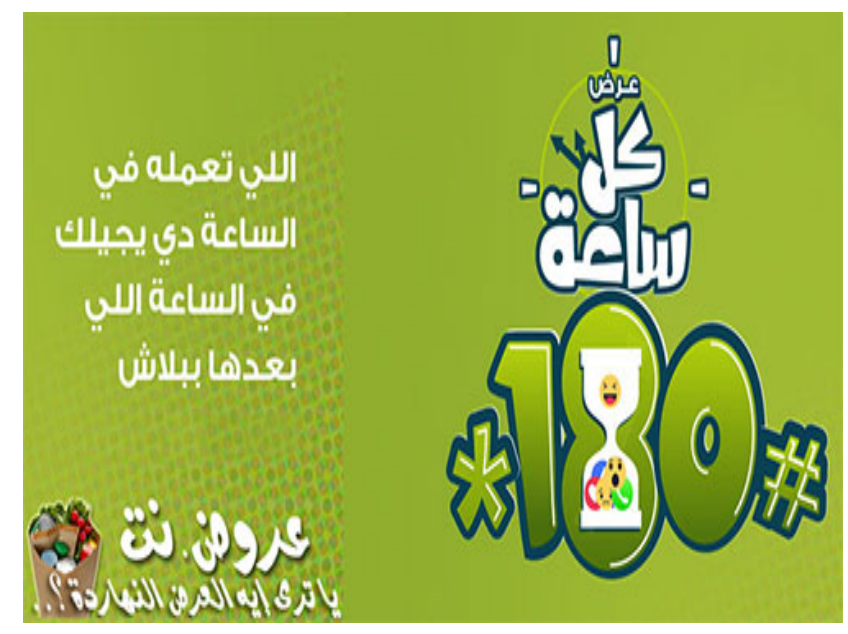

Figure 10. Egyptian advertising (Etisalat Company).

\subsection{Antonyms}

Antonyms, on the hand, as explained by Haddad (2001) play the role of lexical relations as opposites in meaning. This relation between words should imply the positive and negative dimension of a word, especially when the advertiser wants to show the advantages and disadvantages of any products or services or even an idea. So, when the recipient reads about a positive characteristic in an advertisement, she or he should immediately exclude the bad characteristics without seeing explicit words or mentioning its positive and negative aspects in the same context. 


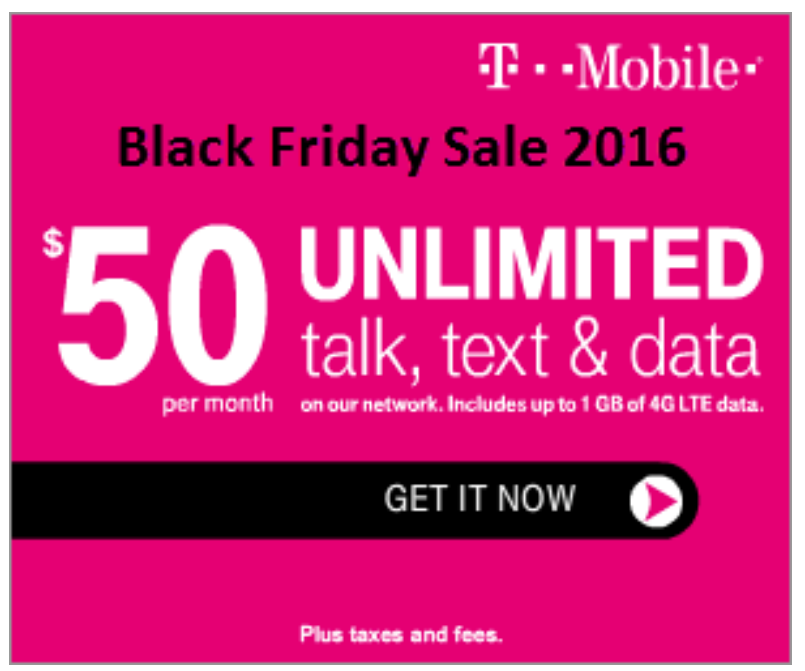

Figure 11. American advertising (T mobile Company).

\subsection{Cohesive Devices}

There is a very specific style that should be followed in writing any advertising and plays a great role in attracting the attention of consumers or recipients. Therefore, everything should be accountable to achieve the goal of advertising with a constructive aim. The advertiser achieves lexical cohesion by repeating lexical items and sometimes paraphrasing them.

Repetition does not only help the recipient to form a lexical cohesion, but it also has a strong impression from the repetition of the key words or items gives the same meanings to emphasize on the real massages. Thus, it appears that repetition of the same word, its synonyms, or their derivations has a strong effect on the reader or the recipient. Repetition of the same words in an advertisement is an effective way to concentrate on the main word and its meanings and purposes. In Arabic discourse, the advertiser may use a word and repeat forms derived from the same root which consists of three consonants and occasionally, of four or five ones. 


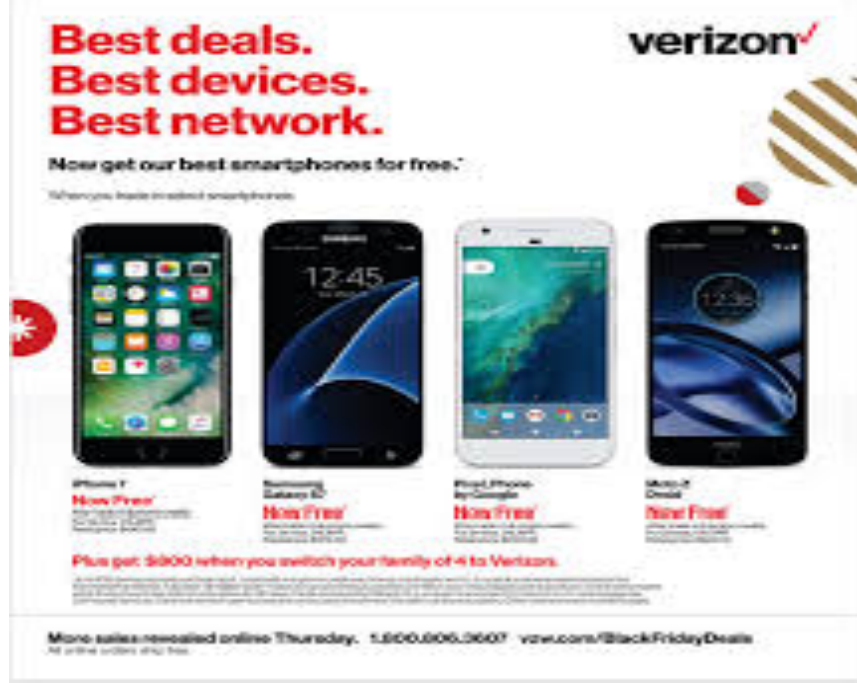

Figure 12. American advertising (Verizon company).

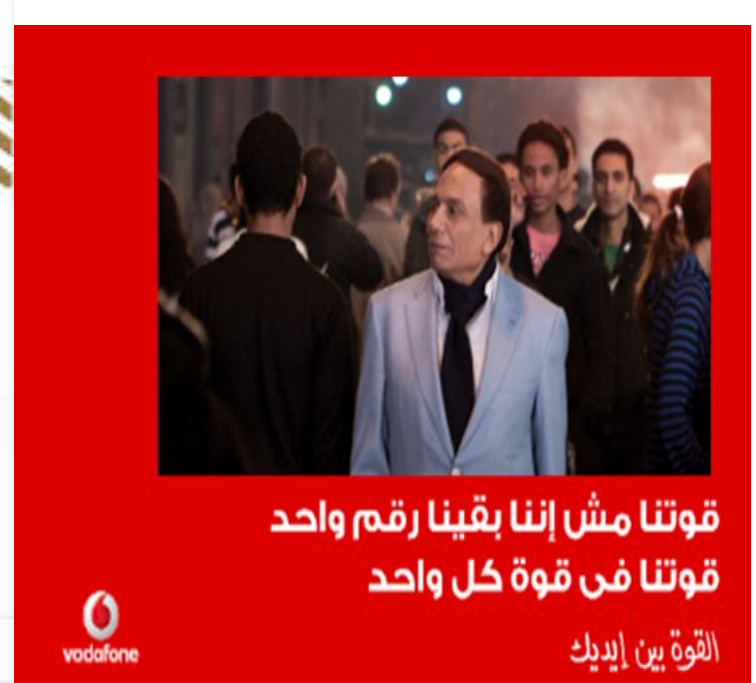

Figure 13. Egyptian advertising (Vodafone company).

This form of repetition, واحد "wahed" One-قوتد our power "quwetna", strengthens and persuades the recipient by making the text more emphatic and rhythmic. Lexical repetition occurs in different cases as in the previous examples when two words or more in advertising are derived from the same root. Repetition in such advertising leads the recipients to the key words which should help them grasp the purpose and meaning of an advertisement.

The advertiser in the above-mentioned example attempts to use different words which, of course, talk about the same meaning of being distinguished. In other words, we can say that the advertiser uses certain strategy while talking about one specific subject by treating it in more than one way; that is, the same idea is expressed in more than one arrangement or choice of words and structures.

\subsection{Simple words/sentences and colloquial language}

The advertiser may also present the information in an informal and intimate way. Therefore, we see him or her talk about a product or idea by using simple words and sentences, in addition to the use of the colloquial language such as the examples mentioned below. 


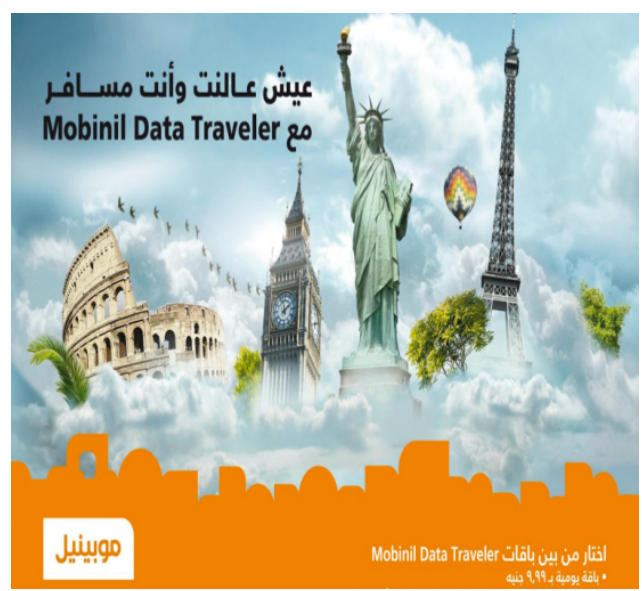

Figure 14. Egyptian advertising.

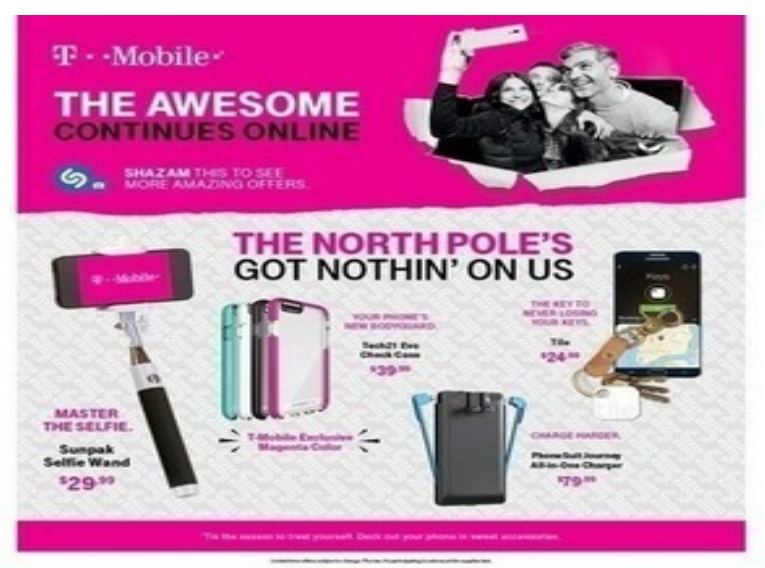

Figure 15. American advertising.

The words عيش عالنت (Live on the internet) is obviously an Egyptian slang term used to express the meaning of spending long time surfing online. On the other hand, the words (The awesome continues online) indicate the usage of American informal style in the word "awesome". This kind of style may help the recipient to follow and understand what an advertiser maintains as a friend as in this form, the advertiser opts for simplicity, truth, believability, and readability. By employing such technique, the advertiser intentionally develops a colorful, warm, human, and personal style. It is always said that since an advertising version is brief, the advertiser tries to use simple, lively, and personal words. They keep saying that the use of rhetorical techniques, and specific strategies like "anaphoric style" build a conversational tone and, in turn, an intimate style between the recipient and the producer of the ad, which helps in persuading and/or manipulating the audience.

In the following example, the anaphoric function, which is the use of a word which refers back to another word already mentioned, is used very frequently in Arabic either within or between sentences. In the Egyptian ad, the word نظام "system" in the clause نظام كلام النت الشهري refers to the previous same words; such as نظام عايز نظام إيه. In the American ad, there is the word "Goodbye" which is repeated to refer to the previous same words. 


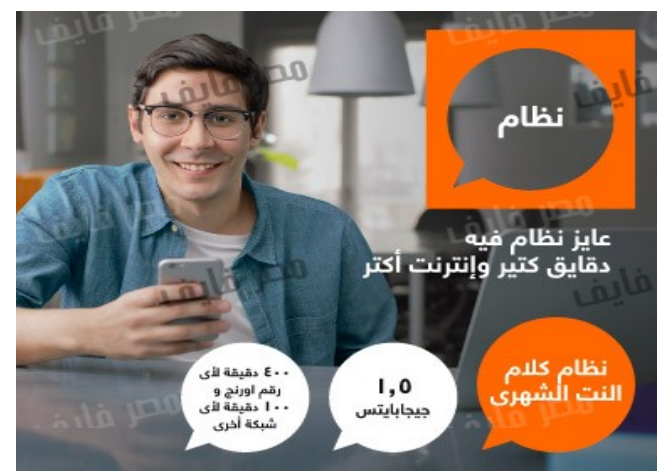

Figure 16. Egyptian advertising.

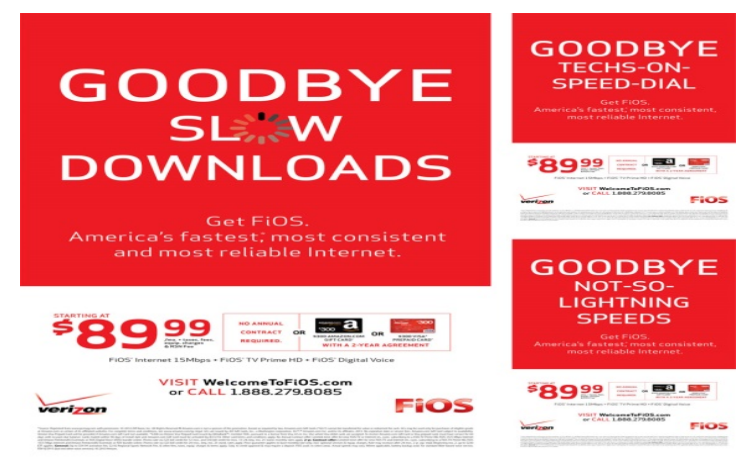

Figure 17. American advertising.

\subsection{Parison / Isocolon}

According to Hussein (2015), parison is a rhetorical term for a succession of phrases, clauses, or sentences of approximately equal length and corresponding structure. Isocolon is a figure of speech in which a sentence is composed by two or more parts perfectly equivalent in structure, length and rhythm: it is called bicolon, (two words) tricolon (three words), or tetracolon (three words). An example for this is

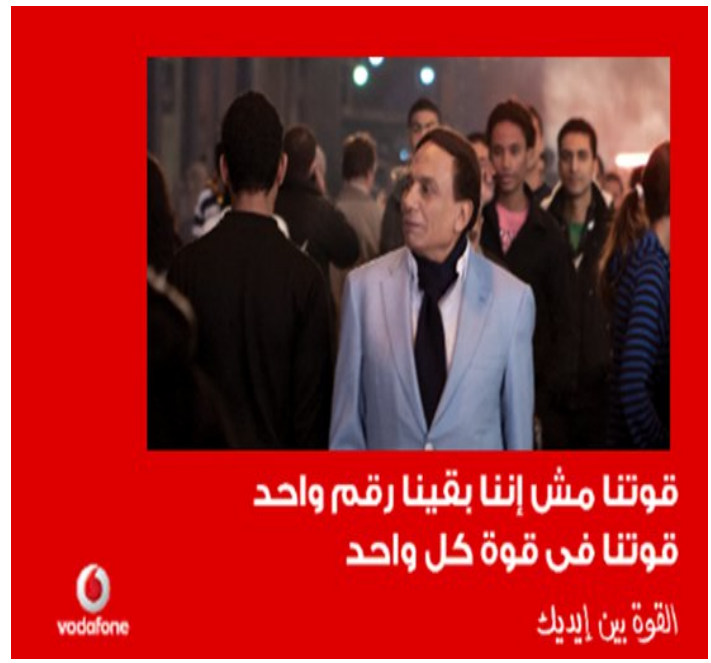

Figure 18. Egyptian advertising.

قوتنا مش إننا بقينا رقم واحد، قوتنا في قوة كل واحد.

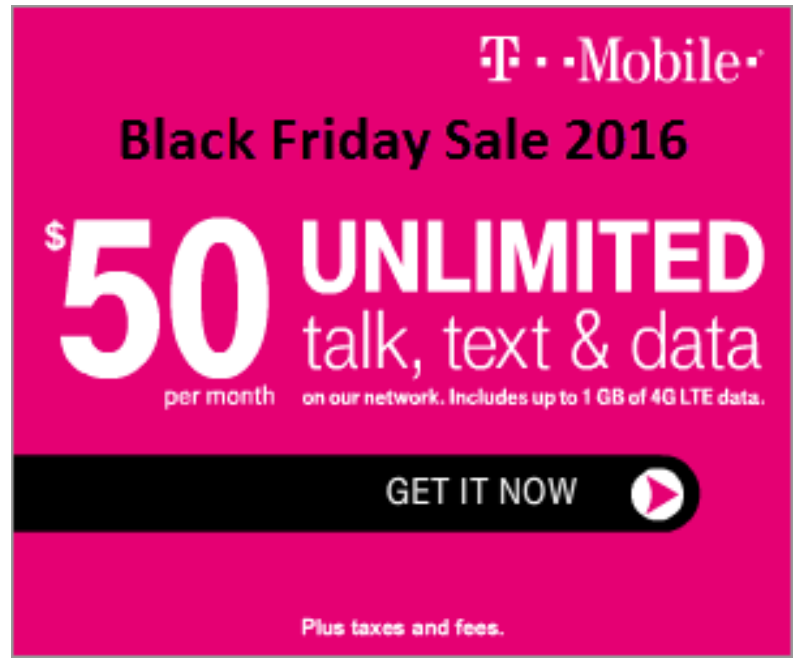

Figure 19. American advertising.

Talk, text, \& data

In the above-mentioned ad, the technique of parison is employed as succession of phrases, of approximately equal length is clear on the ad. The linguistic form of the message works simultaneously with non-verbal one. The speaker deliberately chooses 
such technique to achieve certain main functions: 1) to create short interlocutors' distance thus evoking trust; and 2) to acknowledge the emotional aspect for the audience 3) to convey their notions in a very an indirect way, and therefore advertisers attempt to make the viewers forget the transparent proposition.

Advertisers strongly rely on the objective common knowledge of the audience, which serves as a basis for composition of the meaning of images, lexical items and other linguistic structures. Everything the viewers see on the screen becomes their reality and happens here and now, therefore visual impositions are easier to accept than verbal. By using verbal and visual rhetorical devices, advertisers shorten the distance with the viewers and thus overcome lack of trust and social co-operation between the speaker and the addressee. The poetic function of language is widely exploited by advertisers to make the viewing audience active participants in the construction of meaning. It does much more than simply attract the audience and entertain it. It retains its attention and it creates message and succeeds in helping the advertisers to manipulate the audience.

\section{Concluding remarks}

A thorough analysis of advertising texts revealed that advertisers widely use certain linguistic features in order to manipulate audiences. Ellipsis is an important feature used in advertising. Throughout this study of Egyptian and American advertising data, it shows similar tendencies and parallelism in syntactic structures of mobile phone ads. It seems that the use of the manipulative strategies investigated in this study, such as vagueness, omission and ambiguous claims and interaction of verbal and visual components of ads, are typical of the global advertising discourse.

Almost a large number of advertisings that are examined in this study contained at least one syntactic or stylistic irregularity. Incomplete sentences are a common example of such syntactic irregularity. Often they are the result of omitted words in the sentence. Another important point observed in this study is the slang usage. Slang is often used in advertising in the Egyptian and American samples both to add a contemporary sound and 
to become closer to the audience and be successful in manipulating what they want. Another clear feature employed in the ads as a way for manipulation is inappropriate personification such as "good bye slow downs" which could happen as a result of syntactic or stylistic deviancy, causing a sense of ambiguity.

Cognitively, this study reveals that among the cognitive manipulative strategies generalization. It could be applied through very general and broad concepts with a strong impact on people's mental models. Another cognitive manipulative strategy is the repeated messages which could lead to manipulating the audience of the advertiser's goals. This study reveals that there is a strong connection between manipulation and rhetorical devices in advertising through parallelism, anaphora, antithesis. All of these features are used so as to achieve the effects of emphasizing the value of the ad.

Obviously, advertisers in both sides employ some other linguistic techniques such as, simple sentences of phrases, eye catching title or headline, more emotional with less information. The study shows that advertisers employ synonymy to write an effective and show attractive advertisement with different forms, with the same meaning and purpose. Therefore, the strategic function for using synonyms in advertising where they try to manipulate or convince the reader or recipient to establish certain images about the truth of their proposition. They give the recipient examples to convince him of their interest, ability, and real hope.

The study shows a cognitive dimension for manipulative strategies both at a linguistic and a non-linguistic level and emphasizes the direct connection between cognitive processes and the lexical and syntactic components of language, thereby contributing to understanding of the phenomenon of manipulation, particularly as it exists in the area of advertising: through on the verbal and non-verbal level and, at the linguistic level, through the use of ellipsis and other linguistic items. 


\section{Recommendations}

The major goal of this research has been to investigate the linguistic manipulative strategies in the Egyptian and American mobile phones ads. Accordingly, it recommends for future research to handle the hidden relationships between advertising techniques and the deceptive claims from a consumer perspective. Future researches could focus on mental perceptions of the consumer, exploring the relationships between the degree of deception and masking from one perspective, and the linguistic variation in reaching the advertiser's goal.

Experimental studies are recommended as long as qualitative studies that search more deeply into the underlying meanings delivered by corporate advertisements. The use of semiotic approach would help in this track. This could help in showing for the determining other elements of manipulation and deception and strategies that consumers could use as a way of evaluating the degree of deception. Researchers are recommended to continue the study of visual manipulative discursive ways within advertising and to explore the prevalence and nature of other forms as masks for underlying, deceptive claims.

\section{References}

Abd Alhamid, A. (2007) "The Language of Egyptian Television Advertisements", Journal of Languages \& Translation, Al Azhar University, 41, 1-31.

BRown, G. \& G. YULE (1983) Discourse Analysis, Cambridge: Cambridge University Press.

CHAPMAN, A. (2001) Constructing a gendered consumer identity in a pragmalinguistic model of advertising discourse: the case of Russian and Polish, Ph.D. dissertation, University of California.

CHILTON, P. (2005) "Manipulation, memes and metaphors: The case of Mein Kampf", in L. de Saussure \& P. Schulz (eds.), Manipulation and ideologies in the twentieth century: discourse, language, mind, Amsterdam/Philadelphia: John Benjamins Publishing Company, 15-45.

СоОк, G. (2001) The Discourse of Advertising, London: Routledge. 
CrYSTAL, D. (1997) The Cambridge Encyclopedia of Language, Cambridge: Cambridge University Press

Cuddon, A. J. (1999). The Penguin Dictionary of Literary Terms and Literary Theory, London: Penguin.

DANCIU, V. (2014) "Manipulative marketing: persuasion and manipulation of the consumer through advertising", Theoretical and Applied Economics, volume XXI, No. 2(591), 19-34.

EL-HINNAWI, A. (1992) A lexical study of headlines of advertisements in English, M.A Thesis, Yarmouk University.

FATIHI, A. R. (1992) The Language of advertising and T.V. commercials, New Delhi: Bahri Publications.

GARNHAM, A \& J. OAKHILL (1992)“Aberrant ellipsis: advertisers do, but why?”, English Today, 8(1), 37-40.

GALASIŃSKI, D. (2000) The Language of Deception: A Discourse Analytical Study, UK: SAGE Publications, Inc.

GEIS, L. (1982) The language of television advertising, New York/London: Academic Press.

GodDARD, A. (1998) The Language of Advertising: Written Texts, London: Routledge.

HADDAD, M. (2001) The language of advertising in women's magazines in Jordan, M.A. Thesis, Yarmouk University: Jordan.

HusSEIN, Abbas Lutfi (2015) Advertising Slogans: Rhetorical Characteristics, Journal of Arts Faculty, Faculty of Arts, Basra University.

LEECH, Geoffrey N. (1972) English in Advertising: A Linguistic Study of Advertising in Great Britain (English Language Series), London: Longman.

MedvedeVA, V. (2003) Reklamnaya kommunykatsyya: monohrafyya [Advertising communication: monograph] / E. V.Medvedeva. - M.: Yzdatel'stvo LKY. - 280s.

MCQUARRIE, F. \& G. MICK (1996) "Figures of Rhetoric in Advertising Language", Journal of Consumer Research, 22(4), 424-438.

MCGUiRE, W. J. (1969) "Attitude and attitude change", in G. Lindzey \& E. Aronson (eds.), The handbook of social psychology (2nd ed., vol. 3). Reading, MA: Addison-Wesle, 136-314.

Motes, H., C.B. HiLton \& J. Fielden (1992) “Language, Sentence, and Structural Variations in Print Advertising", Journal of Advertising Research, 32, 63-77.

Nettel, A. \& G. Roque (2011) "Persuasive Argumentation Versus Manipulation", Argumentation, $26,55-69$ 
Dialectologia 24 (2020), 221-251.

ISSN: 2013-2247

SHAVItT, S., T. LOWREY, T \& P. SANG (1992) “Attitude Functions in Advertising: The Interactive Role of Products and Self-Monitoring", Journal of Consumer Psychology, 1(4), 337-364.

ShABBIR, H. \& D. ThWAITES (2007) “The Use of Humor to Mask Deceptive Advertising: It's No Laughing Matter", Journal of Advertising," 36(2), Special Issue on Responsibility in Advertising, 75-85.

TreAsure, J. (1974) "How Advertising Works", in Advertising and Society, New York: New York University Press, 149-168.

VAN DIJK, T. A. (2006) "Discourse and Manipulation", Discourse \& Society, London: SAGE Publications, 17(3), 359-383.

Wrong, D. (1995) Power, its Forms, Bases, and Uses, London: Transaction. 